\title{
Removal and fate of carbamazepine in the microbial fuel cell coupled constructed wetland system
}

\author{
Jingyi Xie ${ }^{1,2,3}$, Haixiao $\mathrm{Li}^{1,2,3}$, Shiyu Wang ${ }^{1,2,3}$, Hao Chen ${ }^{1}$, Wei Jiang ${ }^{4}$, Lin Zhang ${ }^{4}$, \\ Lianjie Wang ${ }^{4}$, Yufeng $\mathrm{Wu}^{5}$, Lirong $\mathrm{Li}^{5}$, Xueqiang $\mathrm{Lu}^{1,2,3^{+}}$ \\ ${ }^{1}$ College of Environmental Science and Engineering, Nankai University, Tianjin, 300350, China \\ ${ }^{2}$ Tianjin Key Laboratory of Environmental Technology for Complex Trans-media Pollution, Tianjin, 300350, China \\ ${ }^{3}$ Tianjin International Joint Research Center for Environmental Biogeochemical Technology, Tianjin, 300350, China \\ ${ }^{4}$ Tianjin Capital Environmental Protection Group Company Limited, Tianjin, 300381, China \\ ${ }^{5}$ Tianjin Eco-Environmental Monitoring Center, Tianjin, 300191, China
}

\begin{abstract}
Carbamazepine (CBZ), which is difficult to remove in the wastewater treatment system and easily forms toxic transformation products during the treatment process, is one of the priority pollutants of pharmaceuticals and personal care products (PPCPs). Increasing attention has been paid to explore their treatment technology without side effects from the treatment products. This study aims to reveal the removal and transformation of CBZ in the microbial fuel cell coupled constructed wetland (CW-MFC) system. The CW-MFC system was operated continuously at room temperature for nearly 80 days. The results show that CW-MFC system can effectively remove CBZ with an average removal rate of $97 \%$. Three transformation products were identified by liquid chromatography-high-resolution mass spectrometry: 2-(2-oxoquinazolin-1(2H)-yl) benzoic acid (TP267), methyl 2-(2-oxoquinazolin-1(2H)-yl) benzoate (TP281), 2-(2,4-dioxo-3,4-dihydroquinazolin-1(2H)-yl) benzoic acid (TP283). Except TP281 in the influent, the other transformation products were formed in the system, which indicated that TP267 and TP283 were the main transformation products of CBZ. The formation pathway of transformation products could be explained by reactions including oxidation, hydrolysis, bond rupture and intramolecular reaction. The results also indicate that the CW-MFC system might be a promising technology for PPCPs treatment.
\end{abstract}

Keywords: Carbamazepine, Constructed wetland, Microbial fuel cell, Transformation product, Wastewater treatment

\section{Introduction}

With the development of technologies related to industrial production, thousands of industrial chemicals are eventually discharged into the aquatic ecosystem. Their exposure may pose a major risk to aquatic ecosystem and human health due to their widespread presence in the environment [1-3]. Pharmaceuticals and personal care products (PPCPs) have received increasing attention in recent years because of their accumulation and persistence in aquatic environments [4,5]. Carbamazepine (CBZ) is listed as an indicator of PPCPs pollution in the environment [6], and also one of the most concerned PPCPs with priority control [7]. The global annual consumption of CBZ is approx- imately 1,000 tons, which leads to the high accumulation of CBZ in the environment [8]. CBZ and its metabolites seriously threatens the ecological environment and human health by producing ecotoxicity and damage to the reproductive system of animals [9, 10], and inducing anticonvulsant hypersensitivity syndrome to human body [11].

Widely-used wastewater treatment processes in wastewater treatment plants (WWTPs), such as activated sludge (AS), anaerobic/anoxic/aerobic $\left(\mathrm{A}^{2} / \mathrm{O}\right)$, usually have little effect on the removal of CBZ, which leads to the concentration of CBZ in the effluent being equal to or even higher than that in the influent. Lee et al. [12] and Pivetta et al. [13] separately investigated the removal of CBZ in WWTP with the AS and $\mathrm{A}^{2} / \mathrm{O}$ treatment processes. Both the
This is an Open Access article distributed under the terms of the Creative Commons Attribution Non-Commercial License (http://creativecommons.org/licenses/by-nc/3.0/) which permits unrestricted non-commercial use, distribution, and reproduction in any medium, provided the original work is properly cited.

Copyright (C) 2022 Korean Society of Environmental Engineers
Received March 03, 2021 Accepted May 07, 2021

${ }^{\dagger}$ Corresponding author

E-mail: luxq@nankai.edu.cn

Tel: +86-22-23501117 Fax: +86-22-23501117

ORCID: 0000-0001-9503-6871 
removal efficiencies of the two processes were less than $10 \%$. Since WWTPs are generally designed to treat the overall organic matter in sewage, not specifically for PPCPs, the sludge retention time (SRT) and hydraulic retention time (HRT) of WWTP is not enough to form a higher microbial biomass concentration to reduce the ratio of food to microorganisms $(\mathrm{F} / \mathrm{M})$, which can increase microbial diversity and improve the removal rate of persistent pollutants, such as CBZ [14]. Therefore, further treatment is required to remove CBZ from the effluent of WWTPs.

The treatment techniques for CBZ are mainly divided into chemical and biological techniques. Chemical techniques, including ozone, photocatalysis, and electrochemical oxidation techniques, can efficiently degrade CBZ in wastewater with a removal rate higher than 90\% [15-17]. However, these techniques are often costly, and toxic intermediate products (e.g. acridine) are easily produced during the process [18]. For biological techniques, membrane bioreactor (MBR) and constructed wetland (CW) are often used, except the above-mentioned conventional wastewater treatment processes (e.g. AS, $\mathrm{A}^{2} \mathrm{O}$ ). Compared with $\mathrm{MBR}$, CW has lower operating cost and no membrane pollution problem [19]. The related research of CW system on the treatment of sulfamethoxazole (SMZ), trimethoprim (TMP), tetracycline (TC) and other antibiotics has shown its application potential for advanced treatment of PPCPs [20]. However, CW has moderate performance in CBZ treatment with removal rate of 50\%-70\% [21, 22]. Microbial fuel cell coupled constructed wetland system (CW-MFC) is an alternative process technology in order to improve the treatment performance of CW for CBZ. MFC system is supposed to enhance the microbial activity in the system and thus the treatment performance [23-25]. MFC could be easily combined with CW because that they are both biological systems engaged in the degradation of organic matter, and the redox gradient required by the MFCs can be formed naturally in the CWs according to the flow direction and the wetland depth [26].

The first CW-MFC study was conducted by Yadav et al. [27], which showed its high efficiency in the treatment of refractory pollutants. CW-MFC was also used in the treatment of PPCPs in wastewater, including sulfadiazine, sulfamethoxazole, tetracycline, etc. [28-30]. It was found that the removal performance of CBZ in CW-MFC system was better than that of CW system [31]. However, most of studies focused on PPCPs treatment performance and its influencing factors, and relatively few studies were related to the transformation and fate of PPCPs, especially for CW-MFC. It is known that CBZ will form transformation products during the degradation process, some of which may be more reactive and toxic than the parent compound [18]. Therefore, the knowledge gap in identification and analysis of CBZ transformation products and degradation pathways in CW-MFC is critical to better assess the state-of-art and further application of CW-MFC [32-34].

In order to understand the transformation and fate of CBZ in CW-MFC, the CBZ removal performance of CW-MFC was investigated in a laboratory environment. While investigating the removal rate of $\mathrm{CBZ}$, the transformation products of CBZ in the system were identified, and the degradation pathways were speculated according to the possible reactions.

\section{Materials and Methods}

\subsection{Experimental Setting}

As shown in Fig. 1, the reactor of CW-MFC is constructed using a cylindrical plastic container $(20 \mathrm{~cm}$ in diameter and $40 \mathrm{~cm}$ in height). The inlet and outlet of wastewater are set at the bottom and top of the reactor, and the sampling points of water are set at three different depths viz. $10 \mathrm{~cm}$ (S1), $20 \mathrm{~cm}$ (S2) and 30 cm (S3) from the top of reactor. This set ensured that the water samples were taken from the areas between the inlet and the anode, around the anode, and between the anode and the cathode, respectively.

For the CW-MFC reactor, from bottom to top there are five layers: water distribution layer (4 $\mathrm{cm}$ in depth), bottom layer (11 cm in depth), anode (5 cm in depth), middle layer $(11 \mathrm{~cm}$ in depth), and cathode ( $3 \mathrm{~cm}$ in depth). The bottom layer and the middle layer are filled with quartz sands of $2-3 \mathrm{~mm}$ in size. While the anode and cathode were made of granular activated carbon (GAC) (4 mm) with a stainless-steel mesh buried inside. Copper conductors are used to connect the electrodes at the stainless-steel mesh to an external resistance $(1,000 \Omega)$ and the electric circuit data collector (DAM-3032 and DAM-3057, Art Technology Co. Ltd., China).

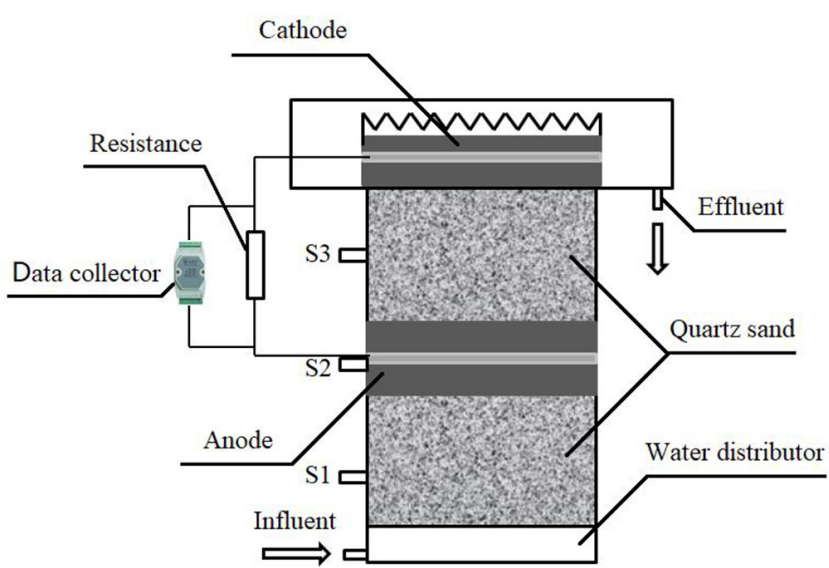

Fig. 1. Schematic diagram of the CW-MFC system. S1-S3: Sampling points. Anode and cathode were composed of granular activated carbon and stainless-steel mesh.

\subsection{Activated Sludge Inoculation}

The functional microbial communities in CW-MFC system were brought by activated sludge inoculation. The activated sludge was collected from Tianjin Wastewater Treatment Plant. The concentration of the sludge was $6 \mathrm{~g}$ dry mass $\mathrm{L}^{-1}$. The sludge $(0.3 \mathrm{~L})$ was added to each reactor during the installation. For sludge acclimatization, synthetic wastewater was pumped into the two reactors with an up-flow mode by a peristaltic pump (BQ80S, Lead Fluid, China). The ingredients of the synthetic wastewater consisted of $0.2 \mathrm{~g} \mathrm{~L}^{-1}$ glucose, $0.135 \mathrm{~g} \mathrm{~L}^{-1} \mathrm{NH}_{4} \mathrm{Cl}$, $0.0277 \mathrm{~g} \mathrm{~L}^{-1} \mathrm{NaH}_{2} \mathrm{PO}_{4} \cdot 2 \mathrm{H}_{2} \mathrm{O}, 0.0138 \mathrm{~g} \mathrm{~L}^{-1} \mathrm{Na}_{2} \mathrm{HPO}_{4} \cdot 12 \mathrm{H}_{2} \mathrm{O}, 0.13$ $\mathrm{g} \mathrm{L}^{-1} \mathrm{KCl}, 0.313 \mathrm{~g} \mathrm{~L}^{-1} \mathrm{NaHCO}_{3}, 0.025 \mathrm{~g} \mathrm{~L}^{-1} \mathrm{MgSO}_{4}$, and $10 \mathrm{ml}$ con- 
centrated trace element solution (50 $\mu \mathrm{g} \mathrm{L}^{-1}$ EDTA, $22 \mu \mathrm{g} \mathrm{L}^{-1}$ $\mathrm{ZnSO}_{4} \cdot 7 \mathrm{H}_{2} \mathrm{O}, 8.2 \mu \mathrm{g} \mathrm{L}^{-1} \mathrm{CaCl}_{2} \cdot 2 \mathrm{H}_{2} \mathrm{O}, 5.1 \mu \mathrm{g} \mathrm{L}^{-1} \mathrm{MnCl}_{2} \cdot 4 \mathrm{H}_{2} \mathrm{O}, 5.0$ $\mu \mathrm{g} \mathrm{L} \mathrm{FeSO}_{4} \cdot 7 \mathrm{H}_{2} \mathrm{O}, 1.1 \mu \mathrm{g} \mathrm{L}^{-1}\left(\mathrm{NH}_{4}\right)_{6} \mathrm{Mo}_{7} \mathrm{O}_{24} \cdot 4 \mathrm{H}_{2} \mathrm{O}, 1.8 \mu \mathrm{g} \mathrm{L} \mathrm{L}^{-1}$ $\mathrm{CuSO}_{4} \cdot 5 \mathrm{H}_{2} \mathrm{O}, 1.6 \mu \mathrm{g} \mathrm{L}^{-1} \mathrm{CoCl}_{2} \cdot 6 \mathrm{H}_{2} \mathrm{O}$ ) for $1 \mathrm{~L}$ wastewater [35]. The flow rate of the peristaltic pump was set at $1 \mathrm{~mL} \mathrm{~min}^{-1}$ in order that the hydraulic retention time (HRT) keeps $2 \mathrm{~d}$. During sludge acclimatization, the voltage of CW-MFC system was monitored by the electric circuit data collector. The sludge acclimatization lasted for $12 \mathrm{~d}$ at a room temperature $\left(25^{\circ} \mathrm{C}\right)$ until the voltage of CW-MFC was stable.

\subsection{Carbamazepine Treatment Experiment}

After the sludge acclimatization, CBZ (over-the-counter) was added to the synthetic wastewater. In order to avoid the extremely high initial pollution load of CBZ for the microbes, the application rate of CBZ was slightly increased from $1.5 \mathrm{mg} \mathrm{L}^{-1}$ to $10 \mathrm{mg}$ $\mathrm{L}^{-1}$ in the first 10 days. When the voltage of CW-MFC system for the $\mathrm{CBZ}$ concentration at $10 \mathrm{mg} \mathrm{L}^{-1}$ was stable, the microbial communities were considered to be adapted to the CBZ containing wastewater. Then, the CW-MFC system was operated continuously at room temperature (ca. $25^{\circ} \mathrm{C}$ ) from June to September, 2019.

The water samples $(50 \mathrm{~mL})$ were collected every two days from the inlet (INF), three sampling points (S1, S2, and S3) and the outlet (EFF) to determine the CBZ removal in the system. CBZ content was measured by the method described in China Pharmacopeia using a spectrophotometer at $285 \mathrm{~nm}$ with a $1-\mathrm{cm}$ cuvette [36]. As the CBZ used in the wastewater was the prescription drugs, the CBZ releasing characteristics in synthetic wastewater was analyzed through a supplementary experiment (Fig. S1). Then the CBZ concentration was corrected according to the increasing proportion of CBZ in the experiment.

\subsection{Operational parameters}

The voltage (V) data were recorded by a personal computer every 10 min to check the stability of the bioelectricity production. The current density $(\boldsymbol{I})$ and power density $(\boldsymbol{P})$ were calculated according to Eq. (1) and (2):

$$
\begin{gathered}
I=U / A R_{\text {ext }} \\
P=U^{2} / A R_{\text {ext }}
\end{gathered}
$$

where $\boldsymbol{U}$ is the voltage, $\boldsymbol{R}_{\mathbf{e x t}}$ is the external resistance, and $\boldsymbol{A}$ is the cross-sectional area of the anode.

The polarization curve and power density curve were established by varying the external resistance within a range of $5 \Omega$ to $10000 \Omega$.

\subsection{Identification of Transformation Products}

After a stable operation for two months, 5 samples from influent, effluent, and three sampling points were collected, and then were stored in the $-5^{\circ} \mathrm{C}$ refrigerator until solid phase extraction (within $24 \mathrm{~h}$ ). The specific operation steps refer to the method described in Ashfaq et al. [37] with modifications. Oasis HLB cartridges (60 $\mathrm{mg}, 3 \mathrm{~mL}$ ) from Waters Corporation (Milford, MA, USA) were conditioned with $5 \mathrm{~mL}$ of methanol followed by $5 \mathrm{~mL}$ of deionized water (HPLC grade) at neutral $\mathrm{pH}$, with a flow rate of $1 \mathrm{~mL} \mathrm{~min}{ }^{-1}$. After the preparation, water samples were percolated through the cartridges with a flow rate of $10 \mathrm{~mL} \mathrm{~min}{ }^{-1}$. After that, the cartridges were rinsed with $5 \mathrm{~mL}$ HPLC grade water, and then were dried in vacuum for 15-20 min to remove excess water. Elution was performed with 2-10 $\mathrm{mL}$ of methanol at $1 \mathrm{~mL} \mathrm{~min}^{-1}$ (CBZ concentration 10-100 ppb). Finally, the extraction solution was collected in a $2 \mathrm{~mL}$ amber glass bottle rinsed with ultrapure water for identification.

A Linear Ion Trap-Orbitrap Mass Spectrometer (LTQ OrbitrapVelos Thermo Scientific, Bremen, Germany) in positive ESI mode was utilized and the MS source parameters for the analysis were set as follows: ion voltage: $3,500 \mathrm{~V}$; ion transfer tube temperature: $300^{\circ} \mathrm{C}$; vaporizer temperature: $350^{\circ} \mathrm{C}$; default charge state: 1; sheath gas flow rate 50 arbitrary units (arb. unit); aux gas flow rate 10 arb. unit; sweep gas flow rate 1 arb. unit; RF lens: $60 \%$, orbitrap resolution: $120 \mathrm{~K}$; scan range: $50-350 \mathrm{~m} / \mathrm{z}$; AGC target: 400000; method duration: $8 \mathrm{~min}$. Chromatographic separation was performed using an Acquity UPLC BEH C18, $1.7 \mu \mathrm{m}$, analytical column, $2.1 \times 50 \mathrm{~mm}$ (Waters). The mobile phase was purified water (A) and methanol (B), both with $0.01 \%$ formic acid. The percentage of B was changed as follows: $0 \mathrm{~min}, 5 \%$; $4 \mathrm{~min}, 90 \%$; $5 \mathrm{~min}, 90 \%$; $5.1 \mathrm{~min}, 10 \%$; and $8 \mathrm{~min}, 5 \%$. The flow rate was $0.4 \mathrm{~mL} / \mathrm{min}$, and the run time was $8 \mathrm{~min}$. The column temperature was set to $30^{\circ} \mathrm{C}$. The transformation products MS2 spectra were conducted at which the collision energy was set to $30 \mathrm{eV}$ (CID, collision induced dissociation).

The final identification of the transformation products was obtained by the following analysis. Firstly, the retention time and accurate mass of the transformation products are obtained by chromatogram and mass spectrometry (Fig. S2 and S3), compared with the database of CBZ transformation products created by collecting literature (Table S1). The structure of the transformation products was further determined by the fragmentation pattern obtained by MS2 spectra (Fig. S4). The mass error (ME) is calculated by [38]:

$$
M E=\frac{M 1-M 0}{M 0} \times 10^{6}
$$

where $\boldsymbol{M}_{\boldsymbol{1}}$ is the measured mass, and $\boldsymbol{M}_{\boldsymbol{0}}$ is the theoretical mass.

Quality assurance and quality control (QA/QC) was conducted to ensure the accuracy of CBZ identification and quantitative results. The limit of detection (LOD) was calculated at $\mathrm{S} / \mathrm{N}$ ratio of 3:1 and the quality control (QC) was based on the standard recovery rate of the effluent and influent samples with spiked concentration of $1 \mathrm{mg} \mathrm{L}^{-1}$ and $10 \mathrm{mg} \mathrm{L}^{-1}$, respectively. LOD and standard recovery rate have been presented in Table S2. In addition, procedural blank was applied for each batch.

\subsection{Bacterial Community Analysis}

Microbial DNA was extracted from electrode substrate (cathode and anode) samples using the E.Z.N.A. ${ }^{\circledR}$ soil DNA Kit (Omega Bio-tek, Norcross, GA, U.S.) for high-throughput sequencing analysis. Bacterial $16 \mathrm{~S}$ rRNA V4-V5 regions were amplified using primers 515F (5'-GTGCCAGCMGCCGCGG-3') and 907R (5'-CCGTCAATT CMTTTRAGTTT-3') [39]. For the 16S rRNA 
polymerase chain reaction (PCR) reactions were performed at $95^{\circ} \mathrm{C}$ for $3 \mathrm{~min}$ followed by 27 cycles of $30 \mathrm{~s}$ at $95{ }^{\circ} \mathrm{C}, 30 \mathrm{~s}$ for annealing at $55^{\circ} \mathrm{C}$, and $45 \mathrm{~s}$ for elongation at $72^{\circ} \mathrm{C}$, and a final extension at $72^{\circ} \mathrm{C}$ for $10 \mathrm{~min}$. The PCR products were extracted from a $2 \%$ agarose gel and further purified using the AxyPrep DNA Gel Extraction Kit (Axygen Biosciences, Union City, CA, USA). High-throughput sequencing was performed by the Illumina Miseq platform at Majorbio Bio-Pharm Technology Co. Ltd. (Shanghai, China). Raw fastq files were quality-filtered by Trimmomatic and merged by FLASH. At the 97\% similarity level, Operational taxonomic units (OTUs) were clustered with a novel 'greedy' algorithm that performs chimera filtering. The sequence of merge partition was used for analysis of the status identification classification, and a bar graph of phylum class level was created to reveal the bacterial composition of the samples.

\subsection{Statistical Analysis}

ANOVA was conducted using the MIXED procedure in SAS 9.4 (SAS Institute Inc., USA) to evaluate data of CBZ of the water samples. Treatment effects were deemed to be significant when $\mathrm{p}<0.05$. Differences among the treatments were identified by multiple comparisons with t-test using the LSMEANS statement in SAS 9.4. The differences between the measured variables of different treatments were significant when $\mathrm{p}<0.05$.

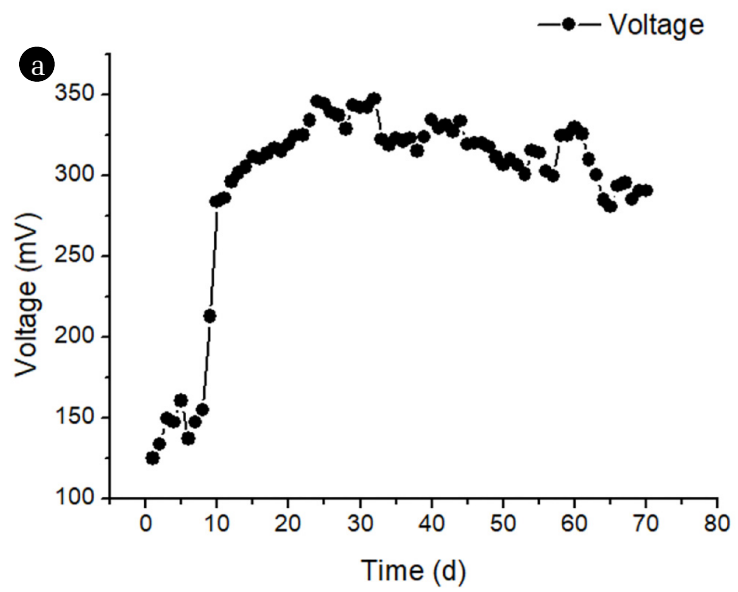

\section{Results}

\subsection{Electricity Generation of CW-MFC}

The CW-MFC system in this study maintained a stable voltage of $315 \mathrm{mV}$ after two weeks (Fig. 2(a)). The polarization curve and power density curve of the CW-MFC system showed that the internal resistance and the maximum power density of the system were $257 \Omega$ and $0.330 \mathrm{~W} \mathrm{~m}^{-2}$ (the corresponding current density was $2.293 \mathrm{~A} \mathrm{~m}^{-2}$ ) (Fig. 2(b)). As shown in Table 1, the electricity generation data of the CW-MFC system are within the range reported in the relevant literatures [27, 39-44].

\subsection{Evolution of Carbamazepine}

The average removal rate of CBZ in the CW-MFC system was $97 \%$ (Fig. 3(a)). In the CW-MFC system, the CBZ concentrations decreased along with the upward water flow direction, and this tendency remained from the start to the end of the experiment, especially the CBZ concentrations of the water in S2, S3 and EFF decreased significantly (Fig. 3(b)).

\subsection{Transformation Products of Carbamazepine}

According to the results of LC-MS of samples at different locations of the CW-MFC system and influent, three major transformation products from CBZ were identified: 2-(2-oxoquinazolin-1(2H)-yl) benzoic acid (TP267), methyl 2-(2-oxoquinazolin-1(2H)-yl) ben-

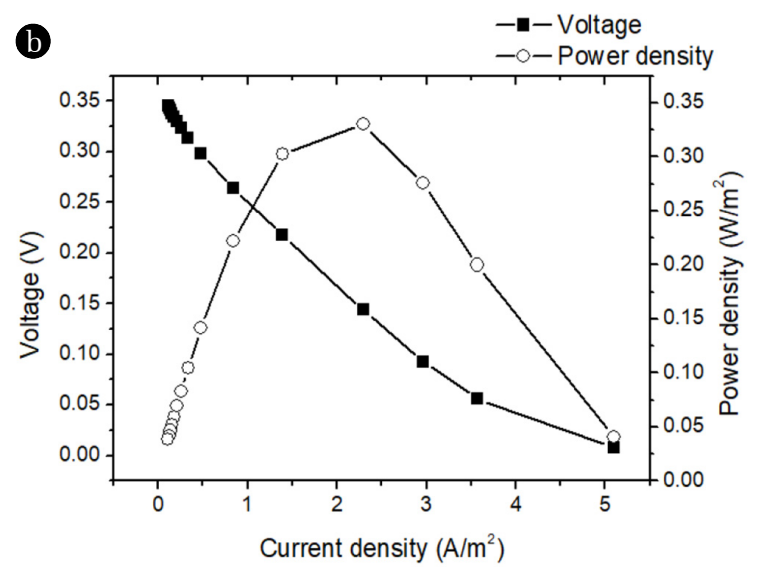

Fig. 2. Electrical performance of CW-MFC. (a) Bioelectricity generation of CW-MFC, (b) Polarization curves and power density curve of CW-MFC.

Table 1. Electricity Generation Obtained from Various CW - MFCs

\begin{tabular}{lccc}
\hline Stable voltage $(\mathbf{m V})$ & Internal resistance $(\Omega)$ & Max power density & References \\
\hline- & - & $0.016 \mathrm{~W} \mathrm{~m}^{-2}$ & Yadav et al. [27] \\
$490-640$ & $156-256$ & $0.012 \mathrm{~W} \mathrm{~m}^{-2}$ & Liu et al. [40] \\
$111-340$ & $209-582$ & $0.055 \mathrm{~W} \mathrm{~m}^{-2}$ & Liu et al. [41] \\
$410-680$ & - & $0.058 \mathrm{~W} \mathrm{~m}^{-2}$ & Zhang et al. [42] \\
235 & - & $0.006 \mathrm{~W} \mathrm{~m}^{-2}$ & Wang et al. [43] \\
$17.6-183$ & - & $0.005 \mathrm{~W} \mathrm{~m}^{-2}$ & Wang et al. [44] \\
265.77 & 373 & $3.714 \mathrm{~W} \mathrm{~m}^{-2}$ & Xu et al. [45] \\
\hline
\end{tabular}



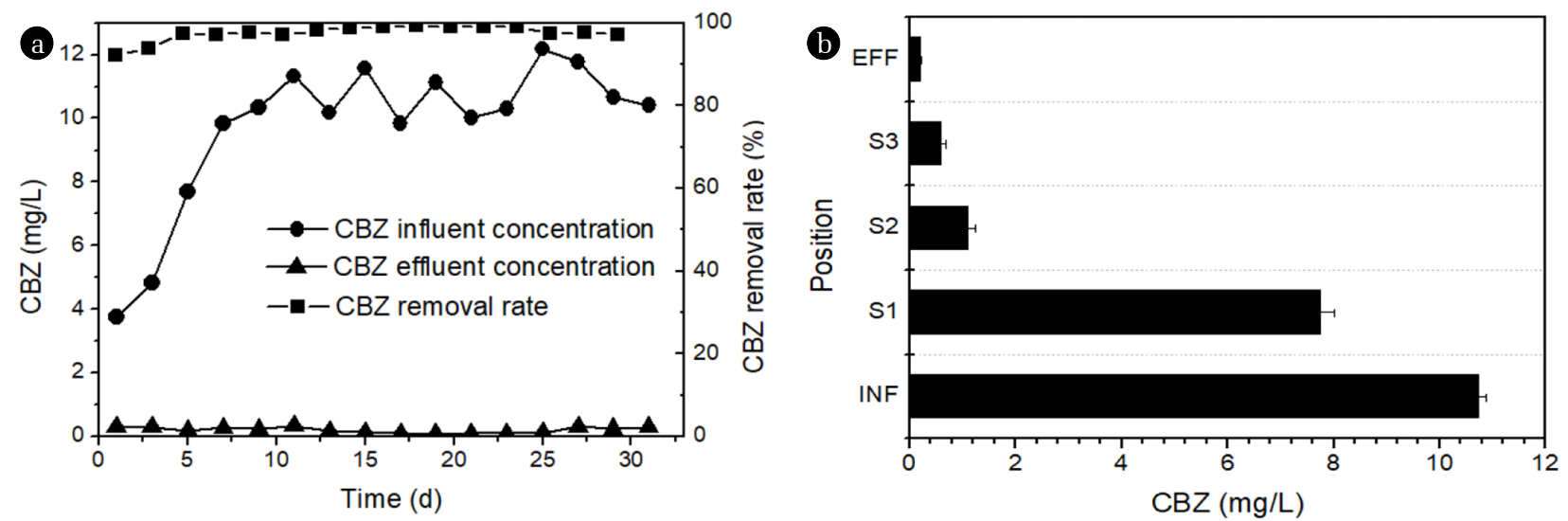

Fig. 3. Removal of CBZ in the CW-MFC system. (a) Temporal variations of influent concentration, effluent concentration and removal rate of CBZ. (b) The average CBZ concentration of the samples at the inlet (INF), three sampling points (S1, S2, and S3) and the outlet (EFF).

Table 2. Identification Information of CBZ and Proposed Transformation Products Formed in the CW-MFC System

\begin{tabular}{|c|c|c|c|c|c|}
\hline Name & Structure & $\begin{array}{l}\text { Predicted } \\
\text { formula }\end{array}$ & $\begin{array}{l}\text { Retention Time } \\
\text { (min) }\end{array}$ & $\begin{array}{r}{[\mathrm{M}+\mathrm{H}]^{+}} \\
\mathbf{p p m})\end{array}$ & $\begin{array}{l}\text { Proposed fragment ions (ppm) and } \\
\text { fragmentation }\end{array}$ \\
\hline CBZ & & $\mathrm{C}_{15} \mathrm{H}_{12} \mathrm{~N}_{2} \mathrm{O}$ & 3.48 & $237.1004(-7.59)$ & 194.0971 (3.61) [-HCNO] \\
\hline TP267 & & $\mathrm{C}_{15} \mathrm{H}_{10} \mathrm{~N}_{2} \mathrm{O}_{3}$ & 3.89 & $267.0737(-12.73)$ & $\begin{array}{c}249.0671(5.22)\left[-\mathrm{H}_{2} \mathrm{O}\right] \\
221.0680(-13.12)\left[-\mathrm{H}_{2} \mathrm{O}-\mathrm{CO}\right]\end{array}$ \\
\hline TP281 & & $\mathrm{C}_{16} \mathrm{H}_{12} \mathrm{~N}_{2} \mathrm{O}_{3}$ & 4.40 & $281.0892(-10.32)$ & $249.0661(1.20)\left[-\mathrm{CH}_{3} \mathrm{O}-\mathrm{H}\right]$ \\
\hline TP283 & & $\mathrm{C}_{15} \mathrm{H}_{10} \mathrm{~N}_{2} \mathrm{O}_{4}$ & 4.18 & $283.0740(9.54)$ & $\begin{array}{c}265.0550(-21.88)\left[-\mathrm{H}_{2} \mathrm{O}\right] \\
237.0541(-49.35)\left[-\mathrm{H}_{2} \mathrm{O}-\mathrm{CO}\right]\end{array}$ \\
\hline
\end{tabular}

zoate (TP281), 2-(2,4-dioxo-3,4-dihydroquinazolin-1(2H)-yl) benzoic acid (TP283) (Table 2, Fig. S2, S3 and S4). Table 1 shows the identification information of these transformation products and the parent compound CBZ. The CBZ and its transformation products were found in the water samples at the positions of S1, S2, S3, and EFF, and the characteristic peaks of CBZ and TP281 were also observed in the LC-MS results of the influent samples (INF) (Fig. 4).

\subsection{Microbial Community Composition}

The microbial community composition of the CW-MFC system is shown in Fig. 5. At the phylum level, the microorganisms on the electrodes of the CW-MFC system mainly include Proteobacteria, Bacteroidota, Firmicutes, and Chloroflexi. For the cathode, the predominant phylum of the microbe was Proteobacteria with a relative abundance of $63 \%$, followed by Firmicutes with a relative abundance of $20 \%$. For the anode, the predominant phyla of the microbes 

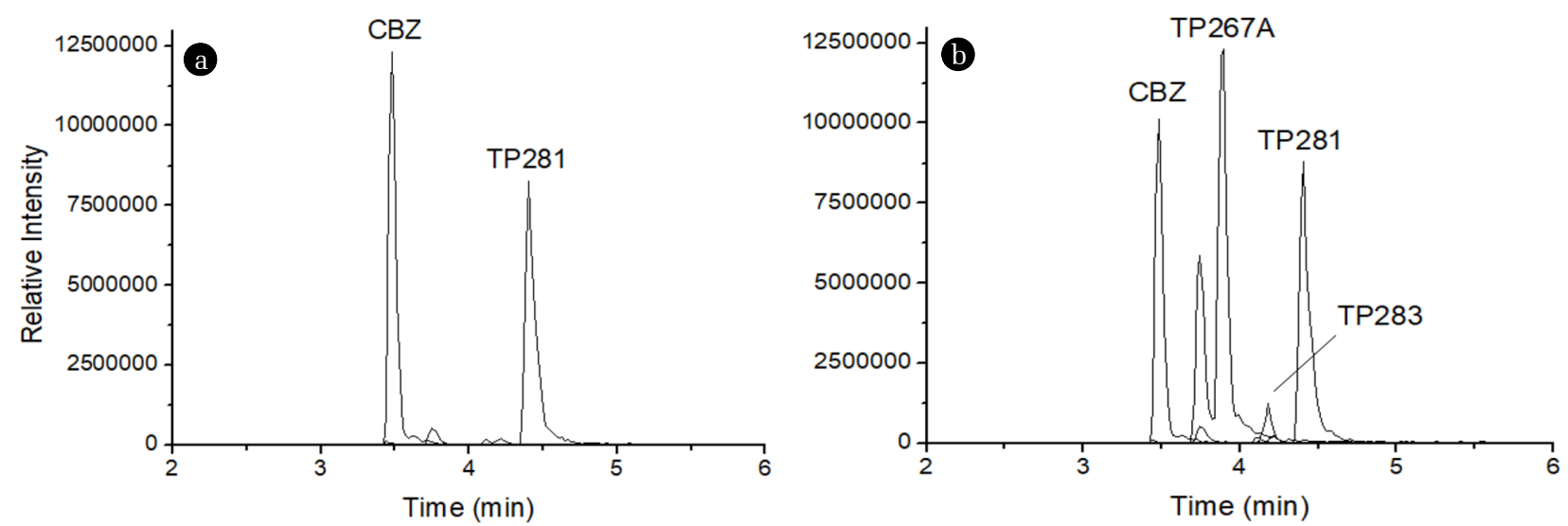

Fig. 4. Chromatogram of CBZ and its transformation products of the influent (a) and effluent (b) samples in the CW-MFC system.

were Bacteroidota and Proteobacteria with relative abundance of $45 \%$ and $22 \%$, respectively.

\section{Discussion}

\subsection{Electricity Generation of CW-MFC}

The power generation performance of CW-MFC system in this study was at a median level compared with other related studies, but it was relatively excellent in related studies under similar configurations and operating conditions. The highest power density of our CW-MFC system $\left(0.330 \mathrm{~W} \mathrm{~m}^{-2}\right)$ is higher than other reported CW-MFC systems (0.005-0.055 $\left.\mathrm{W} \mathrm{m}^{-2}\right)$ with the configuration and operating conditions similar to ours [40, 41], likely because of the lower electrode spacing $(11 \mathrm{~cm})$ promotes the flow of electrons in our system compared to other systems $(20-25 \mathrm{~cm})[40,41] . \mathrm{Xu}$ et al. [45] found the highest power density decreased from around $0.050 \mathrm{~W} \mathrm{~m}^{-2}$ to $0.037 \mathrm{~W} \mathrm{~m}^{-2}$ when the electrode spacing increased from $2 \mathrm{~cm}$ to $5 \mathrm{~cm}$.

\subsection{Removal of Carbamazepine}

The CBZ removal effect of the CW-MFC system in this study is comparable to the results of other CW-MFC systems, and is higher than the results of the CW system. The CBZ removal rates of the CW-MFC system in related studies are 99\% [31], while the CW system is $50-70 \%$ [21, 22]. In order to better compare the removal effect, we also constructed a pure CW system without adding electrodes to evaluate its CBZ removal rate, and the result showed that its average CBZ removal rate of $32 \%$ (not shown as results) was significantly lower than that of the CW-MFC system (Fig. S5(a)). The results indicate that the CW-MFC system constructed in this study has the potential to remove CBZ in wastewater, and some characteristics of the CW-MFC system different from the CW system may be the reason for its better CBZ treatment effect. The first reason is the electrode material. By investigating the removal of CBZ in different positions of the system and comparing with the results in the CW system (Fig. S5(b)), it can be observed that the electrode (S2) was the main area for CBZ removal, which was mainly related to the application of GAC. GAC is considered to be an ideal CW-MFC electrode material, its high specific surface area and porosity can provide a good environment for the attachment and growth of microbial communities [46]. The anode with a larger area than the cathode is more suitable for the growth of biofilm. It was observed that the average bacterial cell density of the anode $\left(5.13 \times 10^{7}\right.$ cells $\left.{ }^{-1}\right)$ was higher than that of the cathode (3.85 $\times 10^{7}$ cells $\mathrm{g}^{-1}$ ) [40]. In addition to the electrode material, the connection of the circuit can promote the growth of the biofilm on the electrode, and affect the structure of the microbial community and increase the enrichment of the functional microbial community. It was observed that the diversity and abundance of microorganisms in the closed-circuit CW-MFC system were higher than those in the open-circuit CW-MFC system and the CW system [25, 39, 47]. The functional microorganisms enriched by CW-MFC electrode mainly include Proteobacteria, Firmicutes, Pseudomonas, Rhodocyclaceae, Nitrospira, etc. [25,39]. Among them, Proteobacteria and Firmicutes at the phylum level and Pseudomonas at the genus level were related to the biodegradation of CBZ [48-50]. Proteobacteria and Firmicutes not only play an important role in the degradation of organic pollutants, but are also important electrochemically active bacteria, which are the main enriched microorganisms in the CW-MFC system [39]. In this study, the microbial composition shows that Proteobacteria and Firmicutes are the main microorganisms at the phylum level (Fig. 5). The enrichment of functional microorganisms helps the effective removal of CBZ. In addition, the electric field in CW-MFC can also promote the interface exchange process between pollutants and microorganisms, which will strengthen the diffusion and mass transfer of organic matter in the biomass, and promote the entry of organic matter into the bottom layer of the biofilm without destroying the microorganisms in the membrane, thereby improving the removal effect of CBZ [51]. The structure and circuit operating environment of CW-MFC can increase the biomass of microorganisms and enrich functional microorganisms. This also explains why the CBZ removal is significantly different between the CW-MFC system and the normal WWTP system.

It should be noted that although CBZ has a low octanol-water partition coefficient $\left(\log K_{o w}=2.7\right)$, the application of GAC may cause significant differences in the removal effect of CBZ in different systems due to adsorption in the short term [52]. For this reason, 


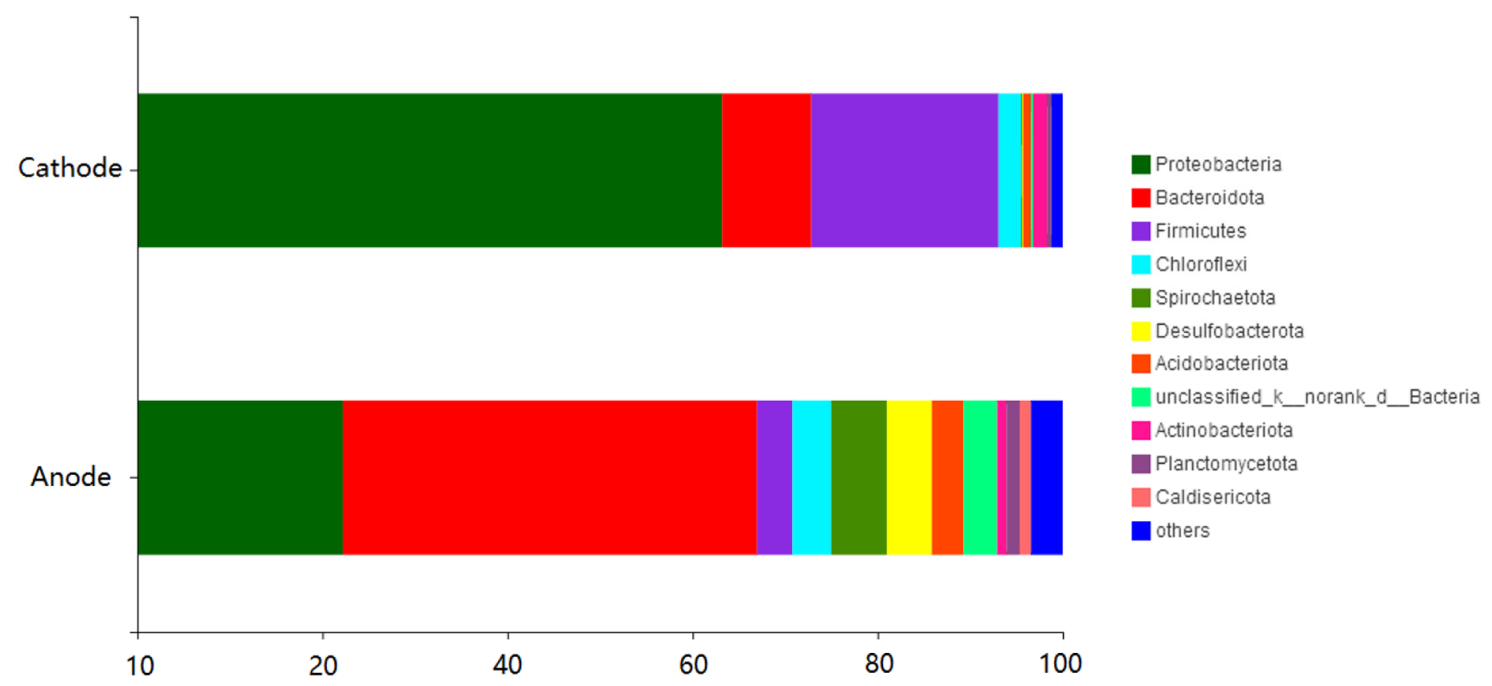

Fig. 5. Microbial community composition of the cathode and anode of the CW-MFC at phylum level.

the study tested the adsorption performance of GAC on CBZ and the results showed that the equilibrium absorption capacity of CBZ on the unit mass GAC was $0.111 \mathrm{mg} \mathrm{g}^{-1}$. According to this result and the GAC mass in the CW-MFC $(1,194 \mathrm{~g})$ and the CBZ mass load in the influent $\left(0.019 \mathrm{~g} \mathrm{~d}^{-1}\right)$, the adsorption can affect the removal of CBZ within a week, and our system maintains a long-term stable high CBZ removal rate. Adsorption onto the substrates was limited compared to the total mass removal during operation. In addition, previous studies have demonstrated that CBZ is relatively stable in the environment, and its half-life in wetland sediments is 165-264 d [53]. Therefore, the long-term stable high CBZ removal rate of the CW-MFC system indicates that the biodegradation of the abundant functional microorganisms on the electrode is the main reason for the effective removal of CBZ other than the adsorption by GAC.

\subsection{The Degradation Pathways of Carbamazepine}

Previous studies have reported two main degradation pathways of CBZ. The first degradation pathway is as briefly described below. As the high frontier electron density of the double bond in the nitrogen-containing heterocycle results in high reactivity [54], it is easily oxidatively cleaved, and then the intramolecular rearrangement reaction causes ring contraction of CBZ and loss of carbamoyl groups. The nitrogen-containing heterocyclic ring shrinks from a seven-membered ring to a six-membered ring, and forms an aldehyde group at the rearranged position. The aldehyde group is further oxidized to carboxyl, and then decarboxylated to form ketone. This degradation pathway mostly occurs in the photodegradation, electrochemical oxidation and active chlorine oxidation processes of CBZ [55-57]. This pathway is known to form acridine that is more toxic than the parent compound $[18,58]$. The second degradation pathway is different from the above pathway. The intramolecular cyclization reaction occurs after the nitrogen-containing heterocyclic ring of CBZ is opened. The carbamoyl group bonds with the aldehyde group to form a new substance, and then further oxidation reaction occurs on the newly formed nitrogen heterocyclic ring and the aldehyde group. This pathway was found upon ozonation of CBZ, ferrate oxidation and biodegradation of activated sludge and sand filters [54, 59, 60].

According to the CBZ transformation products obtained after identification, the degradation pathway of CBZ in our study may be similar to the second degradation pathway, indicating that the CW-MFC system contains bacteria that can effectively degrade CBZ. The presumed degradation pathway is that CBZ was transformed by biological oxidation into reactive and pharmacologically active 1-(2-(3-(o-tolyl) oxiran-2-yl) phenyl) urea (TP253). Then, TP253 was hydrolyzed into 1-(2-(1,2-dihydroxy-2-(o-tolyl) ethyl) phenyl) urea (TP271A). intermediate product 1-(2-(1-hydroxy-2-oxo-2-(o-tolyl) ethyl) phenyl) urea (TP269) was formed by dehydrogenation of TP271A. TP269 may be transformed to 1-(6-formylcyclohexa-2,4-dien-1-yl) -1-(2-formylphenyl) urea (TP271B) through the cleavage of the nitrogen-containing heterocycle. TP271B can be further oxidized to 2-(1-(6-formylcyclohexa-2,4-dien-1-yl) ureido) benzoic acid (TP287). Then, TP267 was formed by the intramolecular reaction of the carbamoyl with the aldehyde group. TP267 can be further oxidized to TP283 or methylated to TP281 (Fig. 6). In addition, the characteristic peak of TP281 observed in the influent indicates that it was not formed by CBZ degradation in the system, but may be transformed from TP267 during the extraction procedure with methanolation [18]. The transformation products formed during the degradation of CBZ have relatively low toxicity and reactivity. The HPTLC bioassay with V. fischeri indicated the microbial toxicity of TP267 and TP283 was not higher than that of the parent compound, and the inhibitory effect of TP283 is less than that of CBZ [59].

Based on the degradation pathways reported in previous studies, the formation process of the transformation products in this study and the possible intermediate products in the process were speculated. No difference was found in the transformation products observed between different positions of the CW-MFC system. Since the relatively aerobic environment in the upper layer of the system 


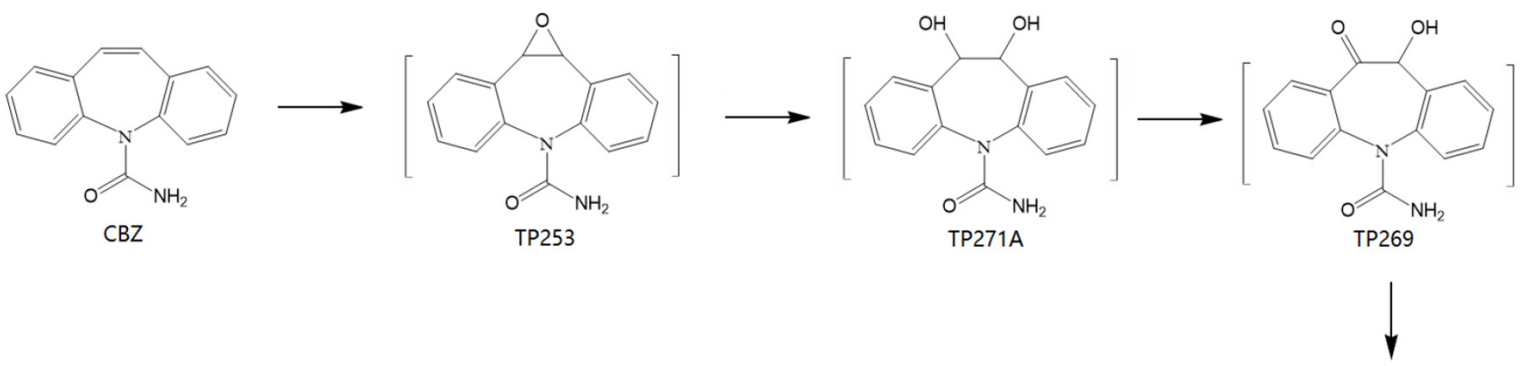

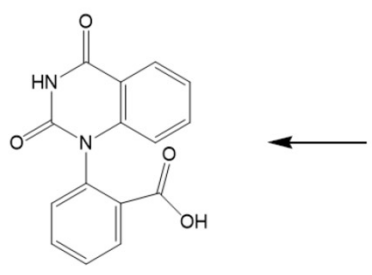

TP283

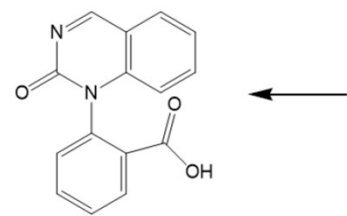

TP267<smiles>COC(=O)c1ccccc1-n1c(=O)ncc2ccccc21</smiles>

TP281

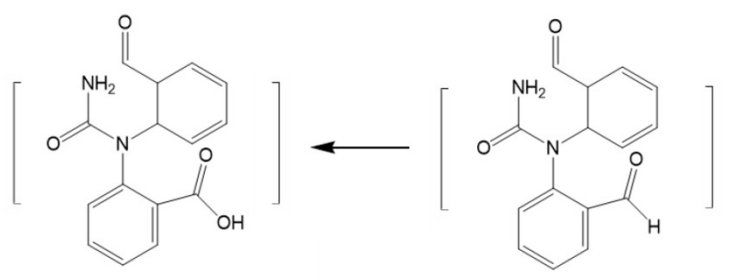

TP287
TP271B

Fig. 6. Proposed degradation pathways to transformation products of CBZ.

may contribute to the degradation of CBZ, the proposed degradation path is most likely to occur in this area. It has been observed in related biological treatment systems that aerobic conditions are more suitable for CBZ degradation than anaerobic conditions [53, 61]. The reason why the same transformation products are observed at different positions may be attributed to the transformation products produced by CBZ degradation that ionize in the solution, and then the ionized ions migrate to the vicinity of the anode area due to electrostatic adsorption, causing them to diffuse in different positions [62].

\section{Conclusions}

This study demonstrates that the CW-MFC system has good performance in CBZ treatment while generating electric energy. The higher removal rate of CBZ in CW-MFC was mainly reflected in the significant decrease of CBZ concentration at the electrode, which indicates that the electrode promotes the transformation and removal of CBZ. Three transformation products were identified by LC-MS in the CW-MFC system, which were 2-(2-oxoquinazolin-1 (2H)-yl) benzoic acid (TP267), methyl 2-(2-oxoquinazolin-1(2H)-yl) benzoate (TP281), 2-(2,4-dioxo-3,4-dihydroquinazolin-1(2H)-yl) benzoic acid (TP283). TP267 and TP283 were the main transformation products. The formation of transformation products could be explained by proposed degradation pathways via intramolecular reactions after cleavage of the double bond in the nitrogen-containing heterocycle of CBZ. Furthermore, the high removal rate of CBZ and low ecological risk of its transformation products for the CW-MFC system found in this study indicate that the CW-MFC system could be a promising technology to remove PPCPs in sewage, although further study is needed to test its performance for co-existence of various PPCPs.

\section{Acknowledgments}

This work was supported by Major Science and Technology Program for Water Pollution Control and Treatment of China (2018ZX07110-007) and the Tianjin Science and Technology Program (18PTZWHZ00110, 18ZXSZSF00250 and 19YFZCSF 00840).

\section{Author Contributions}

J.X. (Ph.D. student) conducted all the experiments and wrote the manuscript. H.L. (Post-Doc.) assisted the data analysis and manuscript writing. S.W. (M.Sc. student), H.C. (Ph.D.), W.J. (Engineer), L.Z. (Engineer), L.W. (Engineer), Y.W. (Engineer), and L.L. (Engineer) 
supported the experiments. X.L. (Professor) initiated and supervised the work.

\section{References}

1. Rasheed T, Shafi S, Bilal M, Hussain T, Sher F, Rizwan K. Surfactants-based remediation as an effective approach for removal of environmental pollutants-A review. J. Mol. Liq. 2020;318:113960.

2. Rashid T, Iqbal D, Hazafa A, Hussain S, Sher F, Sher F. Formulation of zeolite supported nano-metallic catalyst and applications in textile effluent treatment. J. Environ. Chem. Eng. 2020;8:104023.

3. Sher F, Hanif K, Rafey A, et al. Removal of micropollutants from municipal wastewater using different types of activated carbons. J. Environ. Manage. 2020;278:111302.

4. Zhang D-Q, Ni W, Gersberg R, Ng J, Tan S. Performance Characterization of Pharmaceutical Removal by Horizontal Subsurface Flow Constructed Wetlands Using Multivariate Analysis: Water. Clean - Soil Air Water 2015;43:1181-1189.

5. Yang Y, Yong SO, Kim KH, Kwon EE, Tsang YF. Occurrences and removal of pharmaceuticals and personal care products (PPCPs) in drinking water and water/sewage treatment plants: A review. Sci. Total Environ. 2017;596-597:303-320.

6. Sui Q, Cao X, Lu S, Zhao W, Qiu Z, Yu G. Occurrence, sources and fate of pharmaceuticals and personal care products in the groundwater: A review. Emerg. Contam. 2015;1:14-24.

7. Anekwe J, Abou-Elwafa Abdallah M, Harrad S. Pharmaceuticals and personal care products (PPCPs) in the freshwater aquatic environment. Emerg. Contam. 2017;3:1-16.

8. Amin M, Yousefinejad S, Dehghani M, Rahimi S. Catalytic effect of $\mathrm{Fe} @ \mathrm{Fe} 2 \mathrm{O} 3$ nanowires and Fenton process on carbamazepine removal from aqueous solutions using response surface methodology. Glob. J. Environ. Sci. Manag. 2019;5:213-224.

9. Heye K, Becker D, Lütke EC, et al. Effects of carbamazepine and two of its metabolites on the non-biting midge Chironomus riparius in a sediment full life cycle toxicity test. Water Res. 2016;98:19-27.

10. Fraz S, Lee AH, Wilson JY. Gemfibrozil and carbamazepine decrease steroid production in zebrafish testes (Danio rerio). Aquat. Toxicol. 2018;198:1-9.

11. Brown S, Dauterive R. Anticonvulsant Hypersensitivity Syndrome Secondary to Carbamazepine. Proc (Bayl Univ Med Cent) 2017;30:94-96.

12. Lee S-H, Kim K-H, Lee M, Lee B-D. Detection status and removal characteristics of pharmaceuticals in wastewater treatment effluent. J. Water Process. Eng. 2019;31:100828.

13. Pivetta R, Rodrigues-Silva C, Ribeiro A, Rath S. Tracking the occurrence of psychotropic pharmaceuticals in Brazilian wastewater treatment plants and surface water, with assessment of environmental risks. Sci. Total Environ. 2020;727:138661.

14. Verlicchi P, Al Aukidy M, Zambello E. Occurrence of Pharmaceutical Compounds in Urban Wastewater: Removal, Mass Load and Environmental Risk After a Secondary Treatment -A Review. Sci. Total Environ. 2012;429:123-155.

15. Moztahida M, Jang J, Nawaz M, Lim S-R, Lee D. Effect of rGO loading on Fe3O4: A visible light assisted catalyst material for carbamazepine degradation. Sci. Total Environ. 2019;667: 741-750.

16. Minella M, Bellis N, Gallo A, et al. Coupling of Nanofiltration and Thermal Fenton Reaction for the Abatement of Carbamazepine in Wastewater. ACS Omega 2018;3:9407-9418.

17. Aguilar C, Vazquez-Arenas J, Castillo-Araiza C, et al. Improving ozonation to remove carbamazepine through ozone-assisted catalysis using different $\mathrm{NiO}$ concentrations. Environ. Sci. Pollut. Res. 2020;27:22184-22194.

18. Golan N, Seiwert B, Riemenschneider C, Reemtsma T, Chefetz B, Hadar Y. Transformation Pathways of the Recalcitrant Pharmaceutical Compound Carbamazepine by the White-Rot Fungus Pleurotus ostreatus: Effects of Growth Conditions. Environ. Sci. Technol. 2015;49:12351-12362.

19. Yao M, Duan L, Wei J, Qian F, Hermanowicz S. Carbamazepine Removal from Wastewater and the Degradation Mechanism in a Submerged Forward Osmotic Membrane Bioreactor. Bioresour. Technol. 2020;314:123732.

20. Zoh K-D, Choi Y-J, Kim L-H. Removal characteristics and mechanism of antibiotics using constructed wetlands. Ecol. Eng. 2016;91:85-92.

21. Hijosa-Valsero M, Reyes-Contreras C, Domínguez C, Becares $\mathrm{E}$, Bayona J. Behaviour of pharmaceuticals and personal care products in constructed wetland compartments: Influent, effluent, pore water, substrate and plant roots. Chemosphere 2016;145:508-517.

22. Nivala J, Kahl S, Boog J, Afferden M van, Reemtsma T, Müller RA. Dynamics of emerging organic contaminant removal in conventional and intensified subsurface flow treatment wetlands. Sci. Total Environ. 2019;649:1144-1156.

23. Wang L, Liu Y, Ma J, Zhao F. Rapid degradation of sulphamethoxazole and the further transformation of 3-amino-5-methylisoxazole in a microbial fuel cell. Water Res. 2015;88:322-328.

24. Zhang Q, Zhang Y, Li D. Cometabolic degradation of chloramphenicol via a meta-cleavage pathway in a microbial fuel cell and its microbial community. Bioresour. Technol. 2017;229: 104-110.

25. Fang Z, Cao X, Li X, Wang H, Li X. Biorefractory wastewater degradation in the cathode of constructed wetland-microbial fuel cell and the study of the electrode performance. Int. Biodeterior. Biodegradation 2018;129:1-9.

26. Doherty L, Zhao Y, Zhao X, et al. A review of a recently emerged technology: Constructed wetland-Microbial fuel cells. Water Res. 2015;85:38-45.

27. Yadav AK, Dash P, Mohanty A, Abbassi R, Mishra BK. Performance assessment of innovative constructed wetland-microbial fuel cell for electricity production and dye removal. Ecol. Eng. 2012;47:126-131.

28. Song HL, Li H, Zhang S, Yang YL, Zhang LM, Xu H, et al. Fate of sulfadiazine and its corresponding resistance genes in up-flow microbial fuel cell coupled constructed wetlands: Effects of circuit operation mode and hydraulic retention time. Chem. Eng. J. 2018;350:920-929.

29. Song HL, Zhang S, Guo J, Yang YL, Zhang LM, Li H, et al. Vertical up-flow constructed wetlands exhibited efficient antibiotic removal but induced antibiotic resistance genes in 
effluent. Chemosphere 2018;203:434-441.

30. Zhang S, Song HL, Yang XL, Li H, Wang YW. A system composed of a biofilm electrode reactor and a microbial fuel cell-constructed wetland exhibited efficient sulfamethoxazole removal but induced sul genes. Bioresour. Technol 2018;256:224-231.

31. Li H, Cai Y, Gu Z, et al. Accumulation of sulfonamide resistance genes and bacterial community function prediction in microbial fuel cell-constructed wetland treating pharmaceutical wastewater. Chemosphere 2020;248:126014.

32. Cunha M, Lima E, Lima D, et al. Removal of captopril pharmaceutical from synthetic pharmaceutical-industry wastewaters: Use of activated carbon derived from Butia catarinensis. J. Environ. Chem. Eng. 2020;8:104506.

33. Bilal M. Covalent organic frameworks as robust materials for sustainable mitigation of environmental pollutants. Chemosphere 2021;270:129523.

34. Sehar S, Sher F, Zhang S, Khalid U, Sulejmanović J, Lima E. Thermodynamic and kinetic study of synthesised graphene oxide-CuO nanocomposites: A way forward to fuel additive and photocatalytic potentials. J. Mol. Liq. 2020;313:113494.

35. Wang Y-K, Sheng G-P, Shi B-J, Li W-W, Yu H-Q. A Novel Electrochemical Membrane Bioreactor as a Potential Net Energy Producer for Sustainable Wastewater Treatment. Sci. Rep. 2013;3:1864.

36. Commission C. Pharmacopoeia of the People's Republic of China. Part 2. Beijing: Chemical Industry Press; 2005.

37. Ashfaq M, Li Y, Wang Y, et al. Occurrence, fate, and mass balance of different classes of pharmaceuticals and personal care products in an anaerobic-anoxic-oxic wastewater treatment plant in Xiamen, China. Water Res. 2017;123:655-667.

38. Borkowski E, Cecati F, Suvire F, et al. Mass spectrometry and theoretical calculations about the loss of methyl radical from methoxilated coumarins. J. Mol. Struct. 2015;1093:49-58.

39. Xu F, Cao FQ, Kong Q, et al. Electricity production and evolution of microbial community in the constructed wetland-microbial fuel cell. Chem. Eng. J. 2018;339:479-486.

40. Liu S, Song H, Li X, Yang F. Power Generation Enhancement by Utilizing Plant Photosynthate in Microbial Fuel Cell Coupled Constructed Wetland System. Int. J. Photoenergy 2013;2013: 15158-15166.

41. Liu S, Song H, Wei S, Yang F, Li X. Bio-cathode materials evaluation and configuration optimization for power output of vertical subsurface flow constructed wetland - microbial fuel cell systems. Bioresour. Technol. 2014;166:575-583.

42. Zhang S, Song HL, Yang XL, Yang YL, Yang KY, Wang XY. Fate of tetracycline and sulfamethoxazole and their corresponding resistance genes in microbial fuel cell coupled constructed wetlands. RSC Adv. 2016;6:95999-96005.

43. Wang J, Song X, Wang Y, et al. Bioenergy generation and rhizodegradation as affected by microbial community distribution in a coupled constructed wetland-microbial fuel cell system associated with three macrophytes. Sci. Total Environ. 2017;607-608: 53-62.

44. Wang J, Song X, Wang Y, Zhao Z, Wang B, Yan D. Effects of electrode material and substrate concentration on the bioenergy output and wastewater treatment in air-cathode microbial fuel cell integrating with constructed wetland. Ecol. Eng.
2017;99:191-198.

45. Xu L, Zhao Y, Tang C, Doherty L. Influence of glass wool as separator on bioelectricity generation in a constructed wetland-microbial fuel cell. J. Environ. Manage. 2018;207:116-123.

46. Lee J-Y, Lee S-H, Park H-D. Enrichment of specific electro-active microorganisms and enhancement of methane production by adding granular activated carbon in anaerobic reactors. Bioresour. Technol 2016;205:205-212.

47. Wang J, Song X, Wang Y, et al. Nitrate removal and bioenergy production in constructed wetland coupled with microbial fuel cell: Establishment of electrochemically active bacteria community on anode. Bioresour. Technol. 2016;221:358-365.

48. Li A, Cai R, Cui D, et al. Characterization and biodegradation kinetics of a new cold-adapted carbamazepine-degrading bacterium, Pseudomonas sp. CBZ-4. J. Environ. Sci. (China) 2013;25:2281-2290.

49. Thelusmond J-R, Kawka E, J Strathmann T, Cupples A. Diclofenac, carbamazepine and triclocarban biodegradation in agricultural soils and the microorganisms and metabolic pathways affected. Sci. Total Environ. 2018;640-641:1393-1410.

50. Tahir K, Miran W, Jang J, et al. Carbamazepine biodegradation and volatile fatty acids production by selectively-enriched sulfate-reducing bacteria and fermentative acidogenic bacteria. J. Chem. Technol. Biotechnol. 2021;96:592-602.

51. Wang Z, Dong J, Liu L, Zhu G, Liu C. Screening of phosphate-removing substrates for use in constructed wetlands treating swine wastewater. Ecol. Eng. 2013;54:57-65.

52. Nurmi TMA, Kiljunen TK, Knuutinen JS. A fugacity model assessment of ibuprofen, diclofenac, carbamazepine, and their transformation product concentrations in an aquatic environment. Environ. Sci. Pollut. Res. 2019;26:328-341.

53. Conkle J, Gan J, Anderson M. Degradation and sorption of commonly detected PPCPs in wetland sediments under aerobic and anaerobic conditions. J. Soils Sediments 2012;12:1164-1173.

54. Hübner U, Seiwert B, Reemtsma T, Jekel M. Ozonation products of carbamazepine and their removal from secondary effluents by soil aquifer treatment - Indications from column experiments. Water Res. 2013;49:34-43.

55. García-Espinoza JD, Mijaylova P, Flores M. Electrochemical carbamazepine degradation: Effect of the generated active chlorine, transformation pathways and toxicity. Chemosphere 2017;192:142-151.

56. Seiwert B, Golan N, Weidauer C, et al. Electrochemistry Combined with LC-HRMS: Elucidating Transformation Products of the Recalcitrant Pharmaceutical Compound Carbamazepine Generated by the White-Rot Fungus Pleurotus ostreatus. Environ. Sci. Technol. 2015;49:12342-12350.

57. Meribout R, Zuo Y, Khodja A, et al. Photocatalytic degradation of antiepileptic drug carbamazepine with bismuth oxychlorides (BiOCl and BiOCl/AgCl composite) in water: Efficiency evaluation and elucidation degradation pathways. J. Photochem. Photobiol. A 2016;328:105-113.

58. Ghasemian S, Nasuhoglu D, Omanovic S, Yargeau V. Photoelectrocatalytic degradation of pharmaceutical carbamazepine using Sb-doped Sn 80\% -W 20\% -Oxide Electrodes. Sep. Purif. Technol. 2017;188:52-59.

59. Elena K, Carsten P, Manfred W, Kathrin B, Ternes Thomas 
A. Transformation of oxcarbazepine and human metabolites of carbamazepine and oxcarbazepine in wastewater treatment and sand filters. Environ. Sci. Technol. 2014;48:10208-10216.

60. Wang S, Hu Y, Wang J. Strategy of combining radiation with ferrate oxidation for enhancing the degradation and mineralization of carbamazepine. Sci. Total Environ. 2019;687:1028-1033.

61. Wilt A, He Y, Sutton N, Langenhoff A, Rijnaarts H. Sorption and biodegradation of six pharmaceutically active compounds under four different redox conditions. Chemosphere 2017;193: 811-819.

62. López-Bernabeu S, Ruiz-Rosas R, Quijada C, Montilla F, Morallon E. Enhanced removal of 8-quinolinecarboxylic acid in an activated carbon cloth by electroadsorption in aqueous solution. Chemosphere 2015;144:982-988. 